\title{
Num velho exemplo, diferentes maneiras de fazer musicologia: uma resenha do livro César Guerra-Peixe: Estudos de Folclore e Música Popular Urbana
}

\author{
Rodrigo Cantos Savelli Gomes (UDESC, Florianópolis, SC)
}

rodrigocantos@hotmail.com

Resenha do livro ARAÚJO, Samuel (org.) César Guerra-Peixe: Estudos de folclore e música popular urbana. Belo Horizonte: Editora da UFMG, 2007. 277p. $\mathbf{R} \$ 40,00$.

Palavras-chave: Guerra-Peixe; musicologia brasileira; estudos musicológicos; música folclórica brasileira.

In an old example, different ways of doing musicology: a review of the book César GuerraPeixe: Estudos de Folclore e Música Popular Urbana

Review of the book ARAÚJO, Samuel (org.) César Guerra-Peixe: Estudos de folclore e música popular urbana. Belo Horizonte: Editora da UFMG, 2007. 277p. $\mathbf{R} \$ 40,00$.

Keywords: Guerra-Peixe; Brazilian musicology; musicology studies, Brazilian folkloric music.

Guerra-Peixe foi amplamente reconhecido como um ilustre compositor que com maestria, à moda nacionalista de sua época, soube mesclar a estética clássica europeia com a cultura popular e folclórica brasileira, como fizeram Villa-Lobos, Guarnieri, Mignone, entre tantos. Bem menos conhecida, no entanto, foi sua produção como pesquisador musicólogo, resgatada e sistematizada no livro Estudos de folclore e música popular urbana.

Classificado modestamente como organizador, Samuel Araújo se lançou nessa aventura histórico-musicológica, vasculhando acervos, bibliotecas, arquivos, depósitos, onde se deparou com manuscritos, transcrições musicais nunca antes publicadas, para dar forma a algo até então inédito em nosso país: uma coletânea com a vasta produção musicológica de Guerra-Peixe, disseminada até então em diversos meios de difícil acesso. Tratava-se, pois, de uma produção praticamente desconhecida pela musicologia brasileira, cuja forma final foi esboçada por Guerra-Peixe antes de sua morte, mas só definitivamente finalizada nesta publicação.
Há não muito tempo atrás, o trabalho musicológico no Brasil tendia a ser algo absorvente e pouco gratificante. A área carecia de profissionais qualificados, na melhor das hipóteses os musicólogos costumavam ser "professores de música, instrumentistas ou regentes que se dedica[vam] aos estudos musicológicos nas horas livres e de modo pouco articulado com suas atividades principais" (NEVES, 1999, p.181). Além de poucos recursos para pesquisas, dificilmente musicólogos podiam ver editados os resultados de seus trabalhos, fazendo com que grande parte da sua possível produção não chegasse a completar seu próprio ciclo, não alçando, assim, sua forma final (NEVES, 1999). 0 trabalho de Samuel Araújo vem, portanto, atender a demanda brasileira, a qual carece de levantamentos sistemáticos na área de música tradicional, folclórica e popular, de coleções e documentações etnográficas que possam contribuir para uma avaliação mais exata da diversidade das culturas musicais brasileiras num período onde estudos costumavam ser escassos e esparsos. 
Diferente, de certo modo, do grupo de "musicólogos nas horas livres", Guerra-Peixe teve a astúcia de integrar suas pesquisas à sua atividade principal como compositor e arranjador, como é o caso de inúmeras de composições inspiradas no material de campo coletado, por exemplo: Inúbia do Cabocolinho (1956), Prelúdios Tropicais (1979), No Estilo da Folia de Reis (1984), entre tantas. Recolher elementos das culturas populares como forma de criar um "grande banco ou reservatório do qual se deveria extrair elementos que revitalizassem a arte 'elevada' ou 'erudita'" (ARAÚJO, 2007, p.17) era uma prática comum entre os compositores da época. 0 diferencial de Guerra-Peixe, no entanto, foi o tratamento dado ao material coletado que, embora pouco valorizado pela academia brasileira, a qual por décadas privilegiou a música europeia em detrimento da cultura local (BÉHAGUE, 1999), foi sistematizado e publicado pelo compositor em diversos meios.

Entre os 44 artigos e 4 esboços, a obra instiga ao menos duas leituras: a de um documento histórico da diversidade cultural brasileira em meados do século $X X$, ao apresentar uma imensa quantidade de instrumentos, vestimentas, apetrechos, danças, repertórios, grupos musicais, fatos e rituais, descritos e transcritos detalhadamente pelo compositor; a de um documento da prática musicológica brasileira, ao ilustrar diferentes abordagens para o tratamento de questões de interesse musicológico, empregadas por Guerra-Peixe nos diversos contextos abordados.

Na primeira parte do livro, onde estão reunidos os artigos publicados na Revista Brasileira de Folclore, Guerra-Peixe segue uma abordagem descritiva predominante dos estudos de folclore, possivelmente inspirado pela linha editorial da própria revista. Aqui o autor busca privilegiar "uma descrição objetiva dos diversos elementos constituintes de determinado sistema musical, isto é, instrumentos musicais, sistemas tonais, formas musicais, escalas, ritmo, metro, harmonia, polifonia, etc, visando uma taxonomia do vasto material utilizado, do que procurar estabelecer significados ou funções da música" (LAVIGNE, 2000, p.40). É uma abordagem se aproxima ao que IKEDA (1998) classificaria como musicografia "ou seja, trabalhos apenas de descrição do objeto estudado ou coleções de músicas e documentos de interesse musical, que propriamente de musicologia, a qual exige análise, interpretação e compreensão dos fatos" (IKEDA, 1998, p.64). Encontram-se aqui descrições bastante detalhadas de manifestações como, por exemplo, dos grupos carnavalescos conhecidos como Cabocolinhos do Recife; das orquestras populares nordestinas, chamadas de Zabumba ou Banda de Pife, entre outros nomes; e o rito de preparação para a morte daqueles que estão agonizando, popularmente conhecido como Re- za-de-defunto, sustentado por longas cantorias à capela. Na segunda seção - um compêndio de Artigos para jornais diários diversos, dirigidos a públicos distintos e com teor e enfoques próprios em cada um deles - é possivel encontrar, além de textos descritivos ao estilo folclorista, abordagens que se aproximam à musicologia comparativa. Nelas o autor procura identificar unidades de modo a reconhecer características próprias de determinadas práticas musicais, apontando para possíveis generalizações, como é o caso dos textos intitulados: Escalas musicais do folclore brasileiro, A execução do pandeiro no Brasil e Em termos de Música Paulista. Na mesma seção são apresentados estudos que enfocam questões relativas à estética musical, onde autor comenta sobre a origem de determinados gêneros musicais, processos de hibridização e questões relativas à massificação do gosto, em especial a hegemonia do gosto carioca no território brasileiro: $V a-$ riações sobre o Baião, Variações sobre o maxixe e A provável próxima decadência do frevo.

A última parte apresenta uma série publicada ao longo do ano de 1952 em uma coluna do Jornal Diário de Pernambuco. A série consiste em um levantamento de obras e compositores pernambucanos dos últimos cem anos, resultado de uma sondagem realizada em acervos de lojas musicais da região especializadas em venda e registro de partituras. 0 autor depara-se aqui com um objeto de estudo próximo à sua realidade artístico-profissional, ou seja, obras de compositores de seu meio social que, assim como ele, transitaram entre a estética clássica europeia e a música popular brasileira. Trabalhando com algo de seu meio e tempo próximo, Guerra-Peixe se posiciona como um severo crítico de arte, ao molde jornalístico opinativo. Além de revelar a público uma lista imensa de musicistas e peças esquecidas pelo tempo, o autor traz pequenos comentários analíticos onde avalia as obras e os compositores de acordo a complexidade técnica e o estilo estético-ideológico empregados nas respectivas composições. Nacionalista ferrenho, Guerra-Peixe é implacável com os puristas da estética europeia e com aqueles que considera de pouca habilidade técnico-musical.

Assim, ao longo dos diversos artigos presentes nesta coletânea, é possivel observar Guerra-Peixe lançando mão de diferentes abordagem (folclorista, etnomusicológica, musicológica, jornalística), adaptando-se de acordo com o meio de publicação e o público alvo. Uma prática hoje pouco comum. Atualmente, musicólogos costumam restringir a publicação de suas pesquisas a revistas cada vez mais especializadas, de pouco conhecimento público, em linguagem rebuscada, raramente, por exemplo, divulgadas em revistas e jornais de ampla circulação. 


\section{Referências bibliográficas:}

ARAÚJO, Samuel (org.) César Guerra-Peixe: Estudos de folclore e música popular urbana. Belo Horizonte: Editora da UFMG, 2007.

BÉHAGUE, Claude. A Etnomusicologia na América Latina. In: SIMPÓSIO DE MUSICOLOGIA II. Anais. Curitiba: Fundação Cultural de Curitiba, 1999, p.41-70.

IKEDA, Alberto T. Musicologia ou Musicografia?: algumas reflexões sobre a pesquisa em música. In: SIMPÓSIO DE MUSICOLOGIA I. Anais. Mesa Redonda II: Perspectivas da Pesquisa Musicológica na América Latina (do séc. XVI ao XX). Curitiba. Fundação Cultural de Curitiba, 1998, p.63-68.

LAVIGNE, Marcos Antônio. Folclore, música folclórica e música popular. In:Seminário Folclore e Cultura Popular:as várias faces de um debate. 2 ed. Rio de Janeiro: Funarte, Cnfp, 2000, p.39-43.

NEVES, José Maria. Alguns problemas da Musicologia na América Latina. In: SIMPÓSIO DE MUSICOLOGIA II. Anais. Curitiba: Fundação Cultural de Curitiba, 1999, p.175-189.

Rodrigo Cantos Savelli Gomes é mestrando em Música (Musicologia-Etnomusicologia) na Universidade Estadual de Santa Catarina (UDESC) e bolsista do Programa Pós-Graduação CNPq/UDESC. Graduado pelo Curso de Licenciatura em Música na mesma instituição, onde foi por três anos bolsista de iniciação científica. Suas últimas pesquisas enfocaram as relações de gênero na música brasileira, em especial no samba, rock, hip-hop e na música negra. Em 2008 recebeu o $3^{\circ}$ Prêmio Construindo a Igualdade de Gênero e foi condecorado com menção honrosa no ano consecutivo. 